\title{
Cogitation on Occupational Stress and Social Support among Hospital Nurses: a Case Study of Zanjan Province, Iran
}

\section{Samira Jafari ${ }^{1}$, Roya Sadeghi ${ }^{2}$ Mohammad- Hossein Baghiani Moghadam', Fatemeh Shojaei $^{3}$, Mitra Ebrahimpoor ${ }^{4 *}$}
${ }^{1}$ Department of Health Education \& Promotion, School of Public Health, ShahidSadoughi University of Medical Sciences and Health Services, Yazd, Iran
${ }^{2}$ Department of Health Education \& Promotion, School of Public Health, Tehran University of Medical Sciences, Tehran, Iran
${ }^{3}$ Nursing school of Abhar, Zanjan University of Medical Sciences, Abhar, Iran
${ }^{4}$ Department of Biostatistics, School of Public Health, Tehran University of Medical Sciences, Tehran, Iran
Study Area:Zanjan Province, Iran
Coordinate: $36.5018^{\circ} \mathrm{N}, 48.3988^{\circ} \mathrm{E}$

Key words: Job Security, Intention to Quit, Job Satisfaction

\section{Introduction:}

Stress is an undeniable part of modern life and it is widely recognized that stress affects Quality of Life(QOL)(Andrades et al., 2007; Ergün et al., 2005; Jafari et al., 2013; Riggs \& Rantz, 2001; Shojaei et al., 2013; Su et al., 2009; Wu et al., 2010). Having a job is supposed to be a way to earn money and/or get socially involved; the problem arises when the job causes more stress. Effects of nurses' QOL on the quality of care has been suggested a long time ago, but nurses in Iran still work under strenuous conditions, are not considered as an independent educated employee, and have lower incomes. Furthermore, due to cultural reasons, the expectations of the patients and their relatives are high from the nurses and their behavior is impolite. Improper working conditions, low social support, and low income have often led to nurses' migration to other countries in the Persian Gulf, Kuwait, Iraq, Australia and various parts of European. However, there are no official records to estimate how many nurses would leave the country whenever they are offered a better chance. Considering the nature of social

\section{Abstract}

Despite extensive research on stress among hospital nurses, the important effects of support and stress on care quality are not yet well established. Similar to other jobs, nurses face stress in their routine working day. The relationship between occupational stress, social support and factors relating to each of them, among Iranian nurses are attempted to correlate. This cross-sectional analyticaldescriptive study was carried out in 2013 in Zanjan province where 248 nurses filled the given questionnaires including Demographic data, Work Factors, Nursing Stress Scale, and Social Integration Scale. Data were analyzed using SPSS 16.oo. In our study, we found that the stress and social support were significantly correlated. Our findings revealed a significant relation between social supports and occupational stress in nurses. Conclusively, support from supervisors and coworkers can help control nurses' stress. In addition, both social support and occupational stress are related to three major components: job satisfaction, job security and others' attitude towards nursing. Therefore, creating a positive attitude towards nursing in society, and a suitable working environment for them is a way to increase their efficiency.

networks, social support, and their moderating effect on stress, it may be possible to increase job satisfaction and support of female nurses in future.

Recently, much has been changed in the nursing profession due to the role of advanced technology. This has made the profession more demanding and increased the need for additional education and skills in the respective field, which altogether can lead to more stress. It has been realized that mental exhaustion is very common in nursing as compared to the other professions. High levels of occupational stress can increase vulnerability to mental illnesses and adversely affect nurses' performance(Su et al., 2009). Considering that most nurses are female, the issue gets more signif icant, because, in many third world countries, such as Iran, women are also responsible for the household chores besides their job for earning source. Nursing has already been reported as a stressful job by various authors (AbuAlRub, 200o; Adeb-Saeedi, 2002; Jafari et al., 2012; Selye, 1979). Although nurses have a higher perception of QOL, their compromises from physical, emotional, mental and social status could not be 
ruled out. As per Selye (1979), "nurses are always supportive but not supported". Studies revealed that a high level of stress reduces job performance(AbuAlRub, 2000) and increases body weight (Zapka et al., 2009). Such stress has already been reported to affects organizational efficiency, intension to quit, absence in duty, job satisfaction, quality / quantity of care and enhancing health-related costs(Wheeler \& Riding, 1994). The most practical method to overcome stress in psychiatric nurses is to offer them the deserving social support. As frequently reported in literature social support can reduce stress and likelihood of nurses' intention to quit while increasing job performance and satisfaction (AbuAlRub, 2004; Fong, 1992; Kipping, 1998; Riggs \& Rantz, 2001; Selye, 1979).

There is a correlation between stress and social support in various other fields of our social structure (Ellenbecker, 2004; Hayhurst et al., 2005). Results observed from infertility clinics clearly demonstrated an inverse correlation between social support and husband's stress level at the beginning of treatment (Schneider \& Forthofer, 2005).

The aim of this study was to investigate the association between stress and social support among nurses in the Northwestern region of Iran. We hope the present piece of work could be helpful to create a clear-cut relationship between occupational stress and social support in nurses, clarify contributing factors, and introduce ideas to improve their quality of life.

\section{Methodology:}

Design: a cross-sectional analytical-descriptive study was carried out in 2013 in Zanjan province. Zanjan is located between Tehran (the capital) and Tabriz (a city near Turkish borders). Its residents are mostly Turks who constitute a big ethnic group in Iran. There are five counties in Zanjan, eight university hospitals, and a total of 30 wards. We visited all the wards and according to the resemblance of function or field, we categorized 12 types of wards. Total 873 nurses were employed at university hospitals in Zanjan province with different academic degrees such as professional technician / technician of anesthesia, and BS / MS in Nursing. The sampling method was proportional to size stratified sampling; where a proportional-to-ward-size number of nurses from each ward of each hospital were selected as explained below.

Participant Enrolment:using sample size for correlation formula $(\alpha=0.05$, conf idence level $=90 \%, r=0.15)$ a sample size of 248 was calculated. To choose the samples, a code was assigned to each nurse from 1 to 873 ; the sample size of each ward was calculated proportional to its size and using random numbers table. Only those who agreed to participate voluntarily were included and individuals emotionally or physically unfit due to loss of a family member, divorce, severe illnesses in the last 6 month were excluded.

Ambient Science (2016)

http://www.caves.res.in/
Data Collection: Nurses themselves filled the questionnaires which included: Demographic and Work Factors, Nursing Stress Scale (Gray-Toft \& Anderson, 1981), and Social Integration Scale (McCloskey, 1990). Demographics questionnaire includes a total of 23 queries. There were 9 queries on personal information; namely age, gender, education, marital status, the number of children, occupation, education of spouse, housing, and family income. There were 14 queries on work factors which are experience (in years), professional interest (high, relatively high, somewhat, relatively low, low), employment type (permanent, long-term, short-term, apprentice-ship), job security (poor, fair, average, good, excellent), job satisfaction (yes, somewhat, no), type of ward, others attitude towards nursing (positive, somewhat positive, negative), intention to quit (not at all, maybe yes, definitely yes, not sure), motivation to continue education (yes, no), disability (yes, no), number of patients (per shift), number of days off (monthly on average), overtime shifts (yes, no), mandatory overtime shifts (yes, no).

NSS questionnaire consists of 34 queries identifying stress agents for nurses while performing their duties. It provides a total stress score as well as scores on each of seven subscales. Each question quantified the frequency of stress experienced by nurses in the hospital environment with a 4-point scale, ranging from o (never) to 3 (very frequently), and subscales includes: death and dying, conflict with physicians, Inadequate preparation, lack of support, conflict with other nurses, workload, and uncertainty concerning treatment. Total score range was 34 to 136, classif ied into 3 groups: low stress (less than 68), moderate stress (103 to 69), and high stress (above 104). The basic Social Integration Scale questionnaire (McCloskey, 1990) contains eight queries measuring social support that employee receives from coworkers. In addition, following McCain \& Marklin, 6 more questions were included in the scale to measure the supervisory support (Rezaee et al., 2006). Responses were received on a 4 -point scale ( $1=$ strongly disagree, $2=$ no comments, $3=$ agree, $4=$ strongly agree) with a total score of 8 to 32 for the colleague's subscale and 6 to 24 for supervisory support subscale.

Reliability and validity of Instruments: Reliability of McCloskey's instrument was measured 0.77 in an earlier study (McCloskey, 1990). Abu al Rub (2010) reported reliability of McCain and Marklin's instrument to be 0.7 (Amarneh et al., 2010). Rezaee et al. (2006) performed adaptation and validation of Iranian version of the Nursing Stress Scale and Social Integration Scale. Content validity of the two scales was confirmed by 16 experts of Nursing and Midwifery of Iran University of Medical Sciences, and to measure reliability of questionnaires testretest method was adopted $(\mathrm{r}=0.76$ for Social Integration 
Scale and $\mathrm{r}=0.74$ for Nursing Stress Scale).

Data Analysis: descriptive results such as mean ( \pm SD) and frequency (percent) have been provided to reveal an overview of the sample. Data were analyzed using multiple linear regressions where the independent variables entered the model based on a stepwise method. Pearson Correlation coefficient was used to quantify the correlation. Statistical analysis was done using SPSS 16.0 (IBM, Chicago, IL, USA).

Ethical considerations: this article reflects the results of a research project approved by Zanjan University of Medical Sciences. All participants signed an informed consent. To preserve personal information, collected data was anonymized and participants were provided with a pocket to confidentially return the questionnaires to the questioner.

\section{Results:}

Demographic Factors: statistical analysis was applied to 241 subjects; seven participants who did not answer all the questions were excluded. Total $206(85.5 \%)$ participants were female within an age range of 22 to 55 years $(32.41 \pm 6.13$ years). Participants' mean working experience was $3.15 \pm 1.06$ years. Total $200(83 \%)$ have a Bachelor's degree in nursing or a related field and $183(77.9 \%)$ were married. Spouses of 113 (46.6\%) nurses hold an academic degree out of which $50.2 \%$ were employed $(50.2 \%)$ and the rest of them were either homemakers or self-employed. Total 110 (45.6\%) nurses perceived other's attitude towards nursing positive and $92(38.2 \%)$ negative. $107(44.4 \%)$ nurses rated their professional interest as relatively high. An average number of days off during a month was only 1.13 \pm 0.33 . Total $169(70.1 \%)$ participants worked overtime out of which 149 $(61.8 \%)$ stated that it was not optional to work overtime. Further, $124(51.5 \%)$ participants were motivated to continue their studies in nursing while working whereas 16 (6.6\%) had the disability (walking abnormalities). Lastly, $129(53.5 \%)$ and $87(36.1 \%)$ ranked high and low in job satisfaction. A detailed summary of other demographic and work factors is presented in Tables 1 \& 2 .

Demographics and work factors associated with perceived occupational stress: as shown in Table-4, multiple regression analysis confirms the effect of demographics and work factors on each subscale of the perceived occupational stress. It seems that job security and satisfaction both are greatly related to most subscales of occupational stress.

Demographics and work factors associated with perceived social support: the multiple regression results are presented in Table-5, assessing the effect of demographics and work factors on the two subscales of social support. Regression results indicate that professional interest, job satisfaction, job security, disability and other's attitude towards nursing have a great effect on perceived support.

Social support and occupational stress: mean social support from colleagues and supervisors were 30.05 \pm 4.14 and $17.95 \pm 3.70$, respectively. Table-3 reveals the scores for each subscale of occupational stress. Pearson's correlation test confirmed our hypothesis regarding the association between occupational stress and social support. Total occupational stress $(103.21 \pm 15.23)$ and social support scores $(47.94 \pm 6.94)$ were significantly related $(r=-0.52$; $\mathrm{P}<0.001$ ); indicating that nurses receiving less support, experienced more stress and vice versa. Figure-1 illustrates the corresponding scatter plot; the pattern of the points depicts the clear linear correlation between the two factors. Due to the effect of multiple variables on both dependent variables, assessing their relationship in presence of other factors was not possible.

Table-1. Descriptive Statistics for Demographic Factors ${ }^{a}$

\begin{tabular}{llll}
\hline Variable & Status & Frequency & Percent \\
\hline Number of Children & None & 53 & 52 \\
& $1-2$ & 41 & 40.2 \\
& 3Or More & 8 & 7.8 \\
\hline Family Income $^{\mathrm{b}}$ & $500>$ & 63 & 26.8 \\
& $500-1000$ & 133 & 56.6 \\
& $1000<$ & 30 & 12.8 \\
& $1500<$ & 9 & 3.8 \\
\hline Housing & Ownership & 130 & 53.9 \\
& Rental & 56 & 23.3 \\
& With Family & 39 & 16.2 \\
& Dorm & 8 & 3.3 \\
& Other & 7 & 2.8 \\
\hline
\end{tabular}

all percentages are calculated based on $n=241$, in case numbers do not add up to 10o, the difference represents unanswered questions. ${ }^{\mathrm{b}}$ in thousand Irls

\begin{tabular}{llll}
\hline \multicolumn{3}{c}{ Table-2. Descriptive Statistics for Work Factors ${ }^{\text {a }}$} \\
\hline Variable & Status & Frequency & Percent \\
\hline Employment Type & Permanent & 81 & 33.6 \\
& Long-Term & 75 & 31.1 \\
& Short-Term & 56 & 23.2 \\
& Apprenticeship & 27 & 11.2 \\
\hline JobSecurity & Poor & 49 & 20.3 \\
& Fair & 49 & 20.3 \\
& Average & 74 & 30.7 \\
& Good & 38 & 15.8 \\
& Excellent & 29 & 12 \\
\hline WardType & OR & 28 & 11.6 \\
& Accident \& & 19 & 7.9 \\
& Emergency & & \\
& Internal Medicine & 4 & 1.7 \\
& CCU & 9 & 3.7 \\
& Neurology & 41 & 17.0 \\
& Endoscopy & 7 & 2.9 \\
& Hemodialysis & 37 & 15.4 \\
& Oncology & 4 & 1.7 \\
& Surgery & 7 & 2.9 \\
& Cardiology & 55 & 22.8 \\
\hline \multirow{2}{*}{ Tyes.in/ } & & & Vol.-03(Sp1):p-28
\end{tabular}




\begin{tabular}{llll} 
& General Wards & 25 & 10.4 \\
Intention to Quit & NotAtAll & 59 & 24.5 \\
& MaybeYes & 72 & 29.9 \\
& Def initelyYes & 37 & $15 \cdot 4$ \\
& NotSure & 73 & 30.3 \\
\hline Number of & $1-6$ & 80 & $43 \cdot 7$ \\
Patients & $7-12$ & 81 & $44 \cdot 3$ \\
(PerShift) & $13-18$ & 18 & 9.8 \\
& $19-24$ & 4 & 2.2
\end{tabular}

all percentages are calculated based on $n=241$, in case numbers do not add up to 100, the difference represents unanswered questions.

\begin{tabular}{lcl}
\hline \multicolumn{3}{l}{ Table-3. Descriptive Statistics for Occupational Stress Subscales } \\
\hline Subscales & Mean & $\begin{array}{l}\text { Standard } \\
\text { Deviation }\end{array}$ \\
\hline Death and Dying & $\mathbf{2 2 . 4 2 9 2}$ & 4.77563 \\
Conflict with physicians & 15.8797 & $\mathbf{2 . 9 8 9 9 2}$ \\
Inadequate Preparation & 8.2905 & $\mathbf{2 . 1 2 8 8 4}$ \\
Lack of Support & 7.4149 & $\mathbf{2 . 4 2 0 8 4}$ \\
Conflict with Other Nurses & 15.0125 & 4.29311 \\
Workload & 18.3195 & 3.54753 \\
Uncertainty Concerning Treatment & 15.8714 & 3.15503 \\
\hline
\end{tabular}

Figure-1. Scatter plot of Occupational stress against Social Support $(r=-.52)$

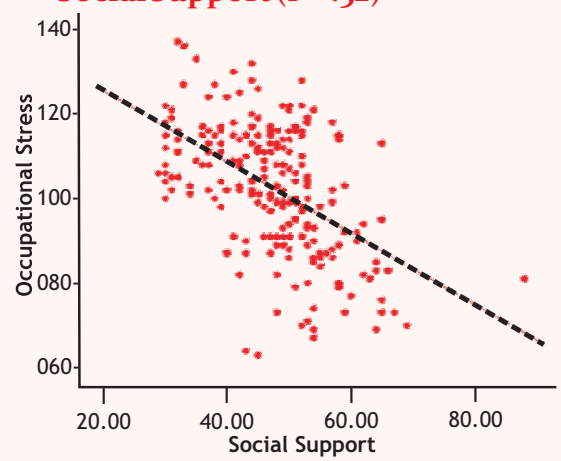

Discussion:

Occupational stress subscales: as per obtained results, nurses perceived themselves to be stressed at work mostly due to death and dying of any patient and workload. It supports the findings reported earlier (Hawkins et al., 2007; Wang et al., 2011). As compared to male, female nurses perceived more occupational stress; they experienced more stress due to workload in off ice as well as in the home. Fang et al. (2014) believe that home-related stressors are predictors of occupational stress among female married hospital nurses. Al-Makhita et al. (2014) also suggested a similar pattern. In Iran, women have less civil liberty, resulting in a limited opportunity for recreation, which otherwise might be helpful in controlling stress. We should also note the certain physiologic differences between men and women. Nurses with less experience are mostly young apprentices (a twoyear mandatory working of nurses in university hospital after graduation and before employment) or newly appointed employees. According to the hierarchical system of nursing in Iran, they work longer hours and have more responsibilities in the ward compared to their seniors; this may be the reason why they are more stressed due to workload.

A significant inverse correlation between experience and occupational stress was also reported by Letvak \& Buck (2008). The inverse effect of age on stress was reported. Presumably, as people get older and concomitantly experienced, they g\& more prepared to cope with the stressful situations. In an earlier study, Najimi et al., (2012) stated that nurses above the age of 30 experience lower levels of stress as compared to their younger coworkers.

Nurses with three or more children feel unprepared for caregiving; obviously, they are more involved with family life and childcare matters, perhaps have less energy to work, and have no time to take extra training courses; a similar type of argument was also given in previous studies (Al-Makhaita et al., 2014; Yu et al., 2014).

Our findings revealed that nurses who work in burn wards were more stressed due to the high level of casualty and death. Generally, burns patients take longer to cure and their conditions are severe. Therefore, nurses get more emotionally involved with the patients, which makes it more painful to confront patients' suffering and death.

Nurses with no motivation to continue education were more stressed due to death and dying, conflict with physicians and inadequate preparation for caregiving; this is attributable to the fact that motivation keeps one up to date in their field which makes them theoretically and clinically eff icient, so physicians trust them and they face fewer conflicts with physicians.

Social Support: nurses, who perceived higher job security and other's attitude toward nursing as positive, received higher social support from their colleagues. Positive minded relatives support nurses and help them, as they understand this profession; not to mention that by being helped, the nurse is less stressed and has fewer conflicts with coworkers. Moreover, by being helped nurses will have the opportunity for promotions and extra courses. This way, through refreshing their knowledge, error rate and change of work shifts (due to personal problems) will reduce, which in turn cuts down the probability of conflict with coworkers. To sum up, positive attitude of others can help nurses in adaptability, problem-solving, as well as role realization. On the other hand, nurses with a disability must perceive higher social support from their supervisors.

Occupational stress and social support: we found that social support is an important mediator factor in occupational stress. Moderate workload and no conflict with other nurses are positive consequences of social support. Mediating effects of support on stress (McCarthy et al., 2010) and emotional exhaustion (Woodhead et al., 
2016) were reported earlier. Feeling supported and trusted by superiors (supervisor and head nurses) can bring about solidarity among nurses. Supporting the nurses by moderating their workload can reduce conflicts. As per our experience, one main reason for conflicts is an unfair division of labor, unequal shifts work and lack of supervisory support. Typically a supported nurse has a close relationship with superiors hence has an appropriate number of shifts and is not expected to work overtime. Again, as per our experience, a head-nurse showing concern for employees can prevent conflicts with a decentralized leadership and organizational decisionmaking power.

As stated in the results, occupational stress and social support both affect job satisfaction. Job satisfaction was higher with less stress and more social support. Besides, satisfied people are usually more compatible with the work environment and coworkers, which will again result in receiving social support.

Study Limitations: the main limitation of this study is the possibility of participation bias, as some nurses refused to participate, in part due to workload and/or because they did not believe that this type of research could improve their work condition. As the adopted questionnaires are self-report measures, validity of responders' answers can be another issue.This large-scale study included all university hospitals of the province. Zanjan province has a highland climate. Access to randomly chosen sample members was difficult considering circulating shifts and inclement weather.

Our sample covered all university hospitals, which may be a limitation regarding generalization of the results to the entire population of Iranian nurses or private hospital nurses. Data collection phase took place before the application of the new policies for Iranian nurses (payment rules changed and work hours reduced after the study). These changes may have affected perceived social support, which is not considered in this study.

Acknowledgements:

We thank the staffs of all university hospitals of Zanjan University of Medical Sciences for their kind participation in this study.

\section{References:}

AbuAlRub, R.F. (2000): Legal aspects of work related stress in nursing. Exploring the issues. AAOHN journal (official journal of the American Association of Occupational Health Nurses), 48(3):131-315.

AbuAlRub, R.F. (2004): Job stress, job performance, and social support among hospital nurses. L. Nur. Scholarship (an off icial publication of Sigma Theta Tau International Honor Society of Nursing / Sigma Theta Tau), 36(1), 73-78.

Adeb-Saeedi, J. (2002): Stress amongst emergency nurses. Aus. Emer. Nur. J., 5(2):19-24.

Al-Makhaita, H.M., Sabra, A.A. \& Hafez, A S. (2014): Predictors of work-related stress among nurses working in primary and secondary health care levels in Dammam, Eastern Saudi Arabia. L. Fam.Community Med., 21(2): 79-84.

Amarneh, B.H., AbAlRub, R.F. \& AbuAlRub, N.F. (2010). Coworkers' support and job performance among nurses in Jordanian hospitals. L. Res. Nur., 15(5):391-401.

Andrades Barrientos, L. \& Valenzuela Suazo, S. (2007): Quality of life associated factors in Chileans hospitals nurses. Revista Latino-Americana de Enfermagem, 15(3):480-486.

Ellenbecker, C. H. (2004). A theoretical model of job retention for home health care nurses. J.Adv. Nur., 47(3):303-310.

Ergün, F.S., Oran, N.T. \& Bender, C.M. (2005). Quality of life of oncology nurses. Cancer Nur., 28(3): 193-199.

Fang, L., Fang, S.H., Chung, Y.H. \& Fang, C.L. (2014): The Predictors of the Job Stress among Female Married Hospital Nurses. Ind. Health.

Fong, C.M. (1992): A model for peak performance. Nurse Educator, 17(4):15-18.

Gray-Toft, P. \& Anderson, J.G. (1981): The Nursing Stress Scale: Development of an instrument. L. Behav. Assess., 3(1):11-23.

Hawkins, A.C., Howard, R.A. \& Oyebode, J.R. (2007): Stress and coping in hospice nursing staff. The impact of attachment styles. Psycho-oncology, 16(6), 563-572.

Hayhurst, A., Saylor, C. \& Stuenkel, D. (2005): Work Environmental Factors and Retention of Nurses. J. Nurs. Care Qual., 20(3):283-288.

Jafari, S., Batebi, A., Sadegi, R., Shojaei, F., Hosseini, M., Ebrahimpoor, M. \& Vaezi, M. (2013): Health related quality of life in nurses. Payesh J., 12(6):671-678.

Jafari, S., Sadegi, R., Batebi, A., Hosseini, M., Ebrahimpoor, M., Shojaei, F. \& Vaezi, M. (2012): The Effects of occupational stress on quality of life and associated factors among hospital nurses in Iran. L. Soc. Devel. Sci., 3(6): 194-202.

Kipping, C. (1998): Mental health nurses' strategies for coping with stress. Ment. Heal. Nurs., 17:18-22.

Letvak, S. \& Buck, R. (2008): Factors influencing work productivity and intent to stay in nursing. Nurs. Econ., 26(3) 159-165.

McCarthy, V.J.C., Power, S. \& Greiner, B.A. (2010): Perceived occupational stress in nurses working in Ireland. Occup. Med., 6o(8): 604-610.

McCloskey, J.C. (1990). Two Requirements for Job Contentment: Autonomy and Social Integration. Image: J. Nurs. Scholarship, 22(3), 140-143.

Najimi, A., Goudarzi, A.M. \& Sharifirad, G. (2012): Causes of job stress in nurses: A cross-sectional study. Iran. j. Nurs. Midwifery Res., 17(4):301-305.

Rezaee, N., Behbahany, N., Yarandy, A. \& Hosseine, F. (2006): Correlation between occupational stress and social support among nurses. Iran J. Nurs., 19(46): 71-78.

Riggs, C.J. \& Rantz, M.J. (2001): A model of staff support to improve retention in long-term care. Nurs. Adminis. Quart., 25(2): 43 .

Schneider, M.G. \& Forthofer, M.S. (2005): Associations of Psychosocial Factors with the Stress of Infertility Treatment. Heal. Soci. Work, 30(3), 183-191.

Selye, H. (1979). The stress of my life: a scientist's memoirs. New York; Toronto; Van Nostrand Reinhold. 
Research ARTICLE

Shojaei, F., Batebi, A., Sadeghi, R., Hoseini, M., Vaezi, M. \& Jafari, S. (2013): Occupational Stress and Its Determinants among Nursing Staff of Hospitals Affiliated To Zanjan University of Medical Sciences in 2011. J.Heal. Develop., 2:74-82.

Su, J.A., Weng, H.H., Tsang, H.Y. \& Wu, J.L. (2009): Mental health and quality of life among doctors, nurses and other hospital staff. Stress Heal., 25(5):423-430.

Wang, W., Kong, A.W.M. \& Chair, S.Y. (2011): Relationship between job stress level and coping strategies used by Hong Kong nurses working in an acute surgical unit. Appl. Nurs. Res., 24(4), 238-243.

Wheeler, H. \& Riding, R. (1994): Occupational stress in general nurses and midwives. Brit. J. Nurs. , 3(10): 527-534.
Woodhead, E.L., Northrop, L. \& Edelstein, B. (2016): Stress, Social Support, and Burnout Among Long-Term Care Nursing Staff. L.Appl. Gerontol. 35(1),:84-105.

Wu, S., Zhu, W., Li, H., Yu, I. T.-S., Lin, S., Wang, X. \& Yang, S. (2010): Quality of life and its influencing factors among medical professionals in China. Inter. Arch. Occup. Environ. Heal., 83(7): 753-761.

Yu, J., Ren, X., Wang, Q., He, L., Wang, J., Jin, Y., ... Yao, Y. (2014): The role of social support on occupational stress among hospital nurses. Inter. J. Clini. Exper. Med., 7(9):3000-3004.

Zapka, J.M., Lemon, S.C., Magner, R.P. \& Hale, J. (2009): Lifestyle behaviours and weight among hospital-based nurses. J.of Nurs. Manag., 17(7):853-86o.

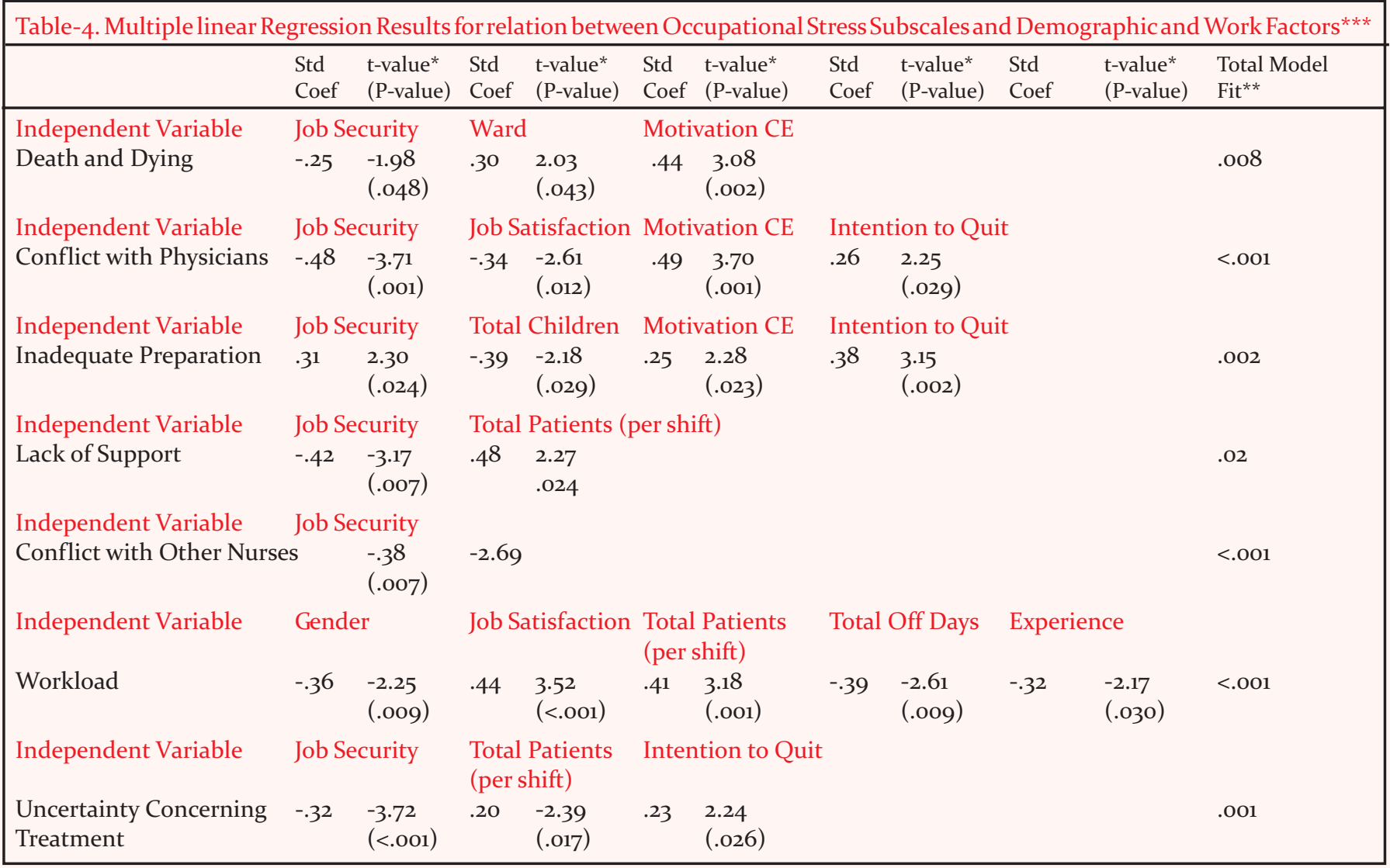

***Each line represents estimated coefficients for the final regression model based on stepwise method.

**F-test has the null hypothesis that there is no linear relationship between the variables.

* The null hypothesis to test the coefficient is: estimated coefficient is zero.

Table-5. Multiple linear Regression Results for relation between Social Support Subscales and Demographic and Work Factors***

\begin{tabular}{|c|c|c|c|c|c|c|c|}
\hline & $\begin{array}{l}\text { Std } \\
\text { Coef }\end{array}$ & $\begin{array}{l}\text { t-value* } \\
\text { (P-value) }\end{array}$ & $\begin{array}{l}\text { Std } \\
\text { Coef }\end{array}$ & $\begin{array}{l}\text { t-value* } \\
\text { (P-value) }\end{array}$ & $\begin{array}{l}\text { Std } \\
\text { Coef }\end{array}$ & $\begin{array}{l}\text { t-value* } \\
\text { (P-value) }\end{array}$ & $\begin{array}{r}\text { Total Model } \\
\text { Fit }^{* *}\end{array}$ \\
\hline Independent Variables & \multicolumn{2}{|c|}{ Job Satisfaction } & \multicolumn{2}{|c|}{ Professional Interest } & Disability & & \\
\hline Support from Supervisors & $.28(.012)$ & 2.61 & $.60(<.001)$ & $5 \cdot 37$ & $.30(.009)$ & 2.75 & $<.001$ \\
\hline Independent Variables & \multicolumn{2}{|c|}{ Job Security } & \multicolumn{3}{|c|}{ Others' Attitude towards Nursing } & & \\
\hline Support from Colleagues & $.31(.006)$ & 2.73 & $.40(<.001)$ & 4.13 & & & $<.001$ \\
\hline
\end{tabular}

${ }^{* * *}$ Each line represents estimated coefficients for the final model based on stepwise regression

${ }^{* *}$ F-test has the null hypothesis that there is no linear relationship between the variables

* The null hypothesis to test the coefficient is: estimated coefficient is zero. 